\title{
State of World Allergy Report 2008: Allergy and Chronic Respiratory Diseases
}

\author{
Ruby Pawankar,* Carlos E. Baena-Cagnani,** Jean Bousquet, $;$ G. Walter Canonica, \& Alvaro A. Cruz,// \\ Michael A. Kaliner, I and Bobby Q. Lanier\#
}

\begin{abstract}
It is widely recognized that the incidence of allergies and allergic diseases is on the rise globally. As an international umbrella organization for regional and national allergy and clinical immunology societies, the World Allergy Organization is at the forefront of a combined united effort across nations and organizations to address this global concern by promoting the science of allergy and clinical immunology, and advancing exchange of information.

The World Allergy Organization's State of World Allergy Reports will provide a biennial review of allergic diseases worldwide, consider their medical and socioeconomic contexts, and propose effective approaches to addressing these problems.

In this first State of World Allergy Report 2008, experts from different regions of the world have attempted to define the extent of the global allergy problem, examine recent trends, and provide a framework for the collaboration among world medicine, science, and government agencies that is needed to address the rapidly developing issues associated with allergy and allergic diseases.
\end{abstract}

Key Words: allergy, allergic diseases, prevalence, asthma, prevention, report

(WAO Journal 2008;Supplement:S4-S17)

W hat may have begun as a crucial species-protecting immune defense against parasites in humans is now ironically responsible for one of the most common maladies, allergy, which contributes to massive deficits in quality of life and, in some cases, length of life.

Allergy represents an immune programming error. Immunoglobulin $\mathrm{E}$ is normally protective against many parasites, but can also cause the release of histamine and other chemical mediators on exposure to otherwise benign proteins present in airborne pollens, molds, animal danders, and food. Does immunoglobulin E confuse the complex DNA code in these proteins with those of its primary target, parasites? Evo-

Received for publication May 1, 2008; accepted May 15, 2008.

From the World Allergy Organization, 555 East Wells Street, Suite 1100, Milwaukee, WI 53202-3823, U.S.A., *Department of Otolaryngology, Nippon Medical School, Tokyo, Japan; **Faculty of Medicine, Catholic University, Cordoba, Argentina; \$Montpellier Hospital, Montpellier, France; §Ospedale San Martino, University of Genova, Genova, Italy; IARIA Scientific Committee, Faculdade de Medicina da Bahia (UFBA), Salvador, Brazil; |Institute for Asthma and Allergy, Wheaton, MD; and \#Fort Worth, TX.

Correspondence: Karen Henley, Global Project Director, World Allergy Organization Secretariat, London, United Kingdom. E-mail: khenley@ worldallergy.org

Copyright (C) 2008 by World Allergy Organization lutionary adaptationists argue that the human immune system may be calibrated to a certain parasitic load: when that parasite burden decreases as society eliminates parasitosis through public health measures, the immune system may become excessively sensitive and respond defensively to harmless substances because of a state of confusion. Exacerbated by an increased exposure to sensitizing allergens, this confusion is manifested through allergic diseases such as asthma, rhinoconjunctivitis, atopic eczema, urticaria, and anaphylaxis.

The current scientific consensus is that higher standards of hygiene may deprive the developing immune response of important immunologic signals during the period from birth to six years, signals that are important for steering the lifelong direction of the immune system response. This hygiene hypothesis, Holgate ${ }^{1}$ argues, "best accommodates the link between allergy and social class, the urban to rural gradient, infant diet, overuse of antibiotics, and the East to West gradient of disease."

Thus, in the zeal to improve standards of health and reduce infectious disease, the world may be discovering that improved living conditions along with the rapid industrialization of developing nations and a changing world climate present opportunities, challenges, and complexities for human health that have never before been considered. Allergic diseases are increasing in prevalence worldwide and are now the most frequent reasons patients seek medical care. Allergies are also becoming more complex, and patients frequently have multiple allergic disorders. Even the less severe allergic diseases can have a major adverse effect on the health of hundreds of millions of patients and diminish quality of life and work productivity. Allergy is a major problem for the 21st century, and this problem is predicted to worsen as this century moves forward.

As the incidence of allergy and associated diseases has increased, the number of health care professionals trained in the diagnosis and treatment of allergy has decreased. As a result, untold numbers of patients go undiagnosed or are undertreated. Many developing countries have few or no allergy-trained physicians to treat millions of allergy and asthma sufferers, and even in developed countries, many highly sophisticated areas have no trained allergists.

The best response to these issues is for the community of world allergists to promote better the science of allergy and clinical immunology and the exchange of information. The World Allergy Organization is at the forefront of attempts to understand, address, and respond to these issues.

In this first State of World Allergy Report, experts from different regions of the world have attempted to define the 
extent of the problem, examine recent trends, and provide a framework for the collaboration of world medicine, science, and government agencies that is needed to address the rapidly developing issues associated with allergy and chronic respiratory disease.

The report opens with a review of the state of allergy and common chronic allergic respiratory diseases in the AsiaPacific region, which hosted the World Allergy Congress in Bangkok in December 2007 (where this report was first announced). The Asia-Pacific region is also the most populous region of the world and encompasses many highly developed nations and numerous emerging economies. A significant increase in the prevalence of allergies in the emerging societies of this region is anticipated as the social and economic environments change to more industrial and postindustrial infrastructures. An overview of the global epidemiology of allergic diseases in the following section provides information on world trends and contrasts the current situation between developed nations and developing economies. The report next outlines the active response to the growing problem of allergic diseases by two major world organizations: the World Allergy Organization and the Global Alliance against Chronic Respiratory Diseases of the World Health Organization. The report concludes with speculation about the changing environmental and social factors that are expected to influence the future global pattern of allergic diseases and considers the resources that will be needed to manage this burgeoning global epidemic. The pharmaceutical industry, in its own response to this growing problem, has for many years worked alongside the scientific community to ensure that scientific discoveries and innovations are put into practice in the service of allergy patients and physicians. Recognizing the importance of this review, members of the pharmaceutical sector are supporting the State of World Allergy Report through an unrestricted educational grant.

\section{REFERENCE}

1. Holgate ST. The epidemic of allergy and asthma. Nature. 1999; 402(suppl):B2-4.

\section{ALLERGY AND ASTHMA: MAJOR PROBLEMS IN THE ASIA-PACIFIC REGION}

Asthma is a chronic inflammatory disease of the airways that is often associated with airway hyperresponsiveness and variable airflow obstruction. Asthma is usually reversible either spontaneously or with treatment. Allergic rhinitis is an immunoglobulin E-mediated inflammation of the nasal mucosa. Asthma and allergic rhinitis are two of the most common chronic respiratory (airway) diseases in childhood, but both of these diseases also affect adults. The prevalence of these diseases increased substantially in many parts of the world during the 20th century. Allergic sensitization, that is, the development of specific immunoglobulin $\mathrm{E}$ antibodies against common allergens, is an important risk factor for asthma, and asthma is often associated with allergic rhinitis.

An estimated 300 million persons worldwide have asthma, approximately $50 \%$ of whom live in developing countries with limited access to essential drugs; therefore, asthma is often poorly controlled in these areas. ${ }^{1}$ Four hundred million persons worldwide have allergic rhinitis. ${ }^{1,2}$

Two large international studies, the International Study of Asthma and Allergies in Childhood (ISAAC) ${ }^{3}$ and the European Community Respiratory Health Survey (ECRHS), have studied the prevalence of asthma and allergic rhinitis worldwide through the use of standardized questionnaires. Both the ECRHS and ISAAC have shown substantial variations in the prevalence of asthma and allergic rhinoconjunctivitis across countries and regions.

\section{ASTHMA AND ALLERGIC RHINITIS: COMORBID CHRONIC ALLERGIC RESPIRATORY DISEASES}

The ISAAC showed that in general, with some exceptions, higher levels of allergic rhinitis or hay fever are observed in communities with higher levels of asthma. Up to $70 \%$ of persons in the ECRHS who reported having asthma also reported having hay fever, and in all centers, hay fever was strongly associated with the presence of asthma. ${ }^{5}$ Some longitudinal studies suggest that the incidence of asthma is more common in those with a history of rhinitis and that the risk is greater in those with hay fever of the longest duration and of the greatest severity and in those with both sinusitis and rhinitis. ${ }^{6}$

\section{ASTHMA AND ALLERGIC RHINITIS IN THE ASIA-PACIFIC REGION}

\section{Increasing Prevalence}

Asia is the world's most populous continent, with a population of almost 4 billion people and many emerging economies. According to recent epidemiological data from ISAAC phase III, asthma and allergic rhinitis have increased in several areas, mostly in low- and middle-income countries. ${ }^{7,8}$ The prevalence of allergic diseases in Asia varies widely but was found to have increased (from $0.8 \%$ to $29.1 \%$ for asthma and from $5 \%$ to $45 \%$ for allergic rhinitis) as communities adopted modern lifestyles and became urbanized.

Time trends in the prevalence of asthma symptoms also showed different regional patterns, that is, a decrease in current wheezing in children aged 13 to 14 years in western Europe and an increase in wheezing children of the same age group in the Asia-Pacific region. Even within the Asian region, there was a wide variation among countries. The prevalence of asthma in Japan increased from 3.5\% in 1982 to $4.6 \%$ in $1992^{9}$ to $9.1 \%$ in 2006 (A. Akasawa, M.D., Ph.D., unpublished data, 2006) and was accompanied by an increase in allergic rhinitis of up to $32 \%$ (A. Akasawa, M.D., Ph.D., unpublished data, 2006). Similarly, 2 surveys performed in Taiwan using an identical method showed that the prevalence of childhood asthma had increased from $1.3 \%$ in 1974 to $5.07 \%$ in 1985 . $^{10}$ More recent ISAAC III data showed that in 13- and 15-yearold children in Taiwan, the overall cumulative and 12-month prevalences of wheezing and rhinitis in the younger children were $8.2 \%$ and $44.4 \%$, respectively, and those in the older children were $6.9 \%$ and $42.2 \%$, respectively. ${ }^{11}$ The percentage of children in Singapore who had experienced asthma at least once increased from $5.5 \%$ in 1967 to $13.7 \%$ in 1987 and to $20.7 \%$ in 1996. In Singaporean preschoolers aged 4 to 6 years, 
the cumulative and previous 12-month prevalences of wheezing were $27.5 \%$ and $16.0 \%$, respectively. Asthma was reported by $11.7 \%$ of this group of children, and the current prevalence of rhinitis was $25.3 \%$.

A field study conducted in four major cities in India with the use of a validated questionnaire showed the overall prevalence of asthma in 2006 to be $2.38 \%{ }^{12}$ In a recent study in rural Bangladesh, the prevalence of asthma in children was $16.1 \% .{ }^{13}$ In contrast, in nonrural Lhasa, Tibet, the prevalences of current wheezing and diagnosed asthma were $0.8 \%$ and $1.1 \%$, respectively. ${ }^{14}$ The prevalence of allergic rhinoconjunctivitis in Tibet was 5.2\%. Even within the same country, the prevalence of asthma differed among various populations. ${ }^{7,8}$ Although overall regional data for adults are scant, between 1\% and $10 \%$ of adults are estimated to have asthma, and between $10 \%$ and $32 \%$ are estimated to have allergic rhinitis.

\section{Triggers and Risk Factors}

Aeroallergens that trigger allergy and asthma vary from area to area in geographically diverse Asia. Although housedust mites are the major triggering allergen in most of Asia, pollens, such as Japanese cedar pollen, are a major cause of allergic rhinitis in Japan. In a study of the prevalence of allergen sensitization among asthma patients in Thailand, house-dust mites (both Dermatophagoides species and Blomia tropicalis) were the most common sensitizing allergens in both pediatric and adult patients with asthma. ${ }^{15}$ Other important allergens, in order of priority, were cockroach and oil palm pollen. In contrast, less than $5 \%$ of patients were sensitive to other pollens and spores. Similarly, in a study of the sensitization profile of the general population in Southeast Asia to house-dust mites, subjects with rhinitis were most sensitive to B. tropicalis, followed by Dermatophagoides pteronyssinus ( $73 \%$ and $50 \%$, respectively). ${ }^{16}$ Dual sensitization was common.

Although genetic factors are important in the manifestation of asthma and allergic rhinitis, the rapid increase in the prevalence of these disorders cannot be attributed to genetic factors alone. Changes in environmental factors also need to be taken into account. In a survey that compared the prevalence of asthma and atopic disorders in Chinese children aged 12 to 18 years in three Asian cities (Hong Kong, Kota Kinabalu, and San $\mathrm{Bu}$, with Hong Kong being the most developed and westernized city), the prevalence of asthma and allergic disorders in children from Hong Kong was 2 to 6 times that in children from the other 2 cities. ${ }^{17}$ Allergic sensitization was a significant factor associated with asthma. The prevalence of atopy in Kota Kinabalu was high (64\%), yet the prevalence of asthma was low (1.9\%). In a cross-sectional prevalence analysis of wheezing, rhinitis, and eczema in Singaporean preschoolers aged 4 to 6 years, the main risk factors for current wheezing and self-reported asthma were family history of allergy, concurrent rhinoconjunctivitis, concurrent chronic flexural rash, and previous respiratory tract infection. ${ }^{18}$ In rural Bangladesh, risk factors associated with wheezing were pneumonia (at ages 0 to 12 months and 13 to 24 months), maternal asthma, paternal asthma, and maternal eczema. ${ }^{13}$

Despite extensive research on genetic, environmental, and lifestyle causes of asthma and on asthma risk factorsincluding pollution, tobacco smoke, diet, urban lifestyle, re- duced early exposure to infections, and viral infections - no single factor has been identified as responsible for the marked geographic variation in or the increasing prevalence of asthma.

\section{Morbidity and Mortality}

Patients with asthma and allergic rhinitis have a reduced quality of life, and the burden of asthma, as assessed by disability-adjusted life-years, ranks $22 \mathrm{nd}$ among all diseases worldwide. ${ }^{19}$ Moreover, asthma in infancy often goes unrecognized and thus untreated.

The Asthma Insights and Reality in Asia-Pacific Study, which looked at patient perceptions of asthma management across Asia, concluded that patients experience frequent and unnecessary symptoms and exacerbations because of a lack of adequate asthma control. ${ }^{20}$ Indeed, $27 \%$ of adults and $37 \%$ of children with asthma in the Asia-Pacific region reported that this condition had resulted in an absence from school or work in the previous year, and $40 \%$ reported being hospitalized, visiting the emergency department or making unscheduled emergency visits to other health care facilities in the previous year. The severity of asthma varied, with Vietnam and China reporting the most patients with severe persistent symptoms. Work absence was highest in the Philippines (46.6\%) and lowest in South Korea (7.5\%). In another survey of parents of children with asthma from four Asian countries, most of the children $(73 \%)$ had preexisting symptoms of allergic rhinitis at the time when asthma was diagnosed, and comorbid asthma and allergic rhinitis substantially affected quality of life and worsened asthma symptoms. ${ }^{21}$

Mortality associated with asthma varies from country to country and seems to be high in countries where access to essential drugs is low. The Global Initiative on Asthma estimates that approximately 250,000 persons die of asthma annually, and the death rate per 100,000 persons with asthma aged 5 to 34 years in highly populated China is greater than $10 \%{ }^{22}$ However, asthma can be controlled with optimal treatment. This has been proven in countries where an asthma management plan was implemented and the morbidity rate subsequently decreased. ${ }^{23}$

\section{Socioeconomic Burden}

The annual costs of treating asthma and allergic rhinitis - both direct costs (hospitalization, medications) and indirect costs (time lost from work, premature death) - are substantial and represent an even heavier burden in societies with emerging economies. The Asthma Insights and Reality in Asia-Pacific survey of urban centers in eight countries in the Asia-Pacific region showed that the annual per-patient direct costs ranged from US \$108 in Malaysia to US \$1010 in Hong Kong. ${ }^{24}$ Total per-patient costs, including productivity costs, ranged from US \$184 in Vietnam to US \$1189 in Hong Kong. Urgent care costs were $18 \%$ to $90 \%$ of the total per-patient direct costs. The economic burden in the Asia-Pacific region was higher than that in the United States in relation to the per capita gross domestic product (13\% in the Asia-Pacific region compared with $2 \%$ in the United States) and per capita health care spending (300\% in the Asia-Pacific region compared with $12 \%$ in the United States). ${ }^{24,25}$ Approximately US \$20 billion are spent globally each year in relation to allergic rhinitis - a 
figure that includes the costs associated with medications, lost work productivity, and physician consultations. Approximately US $\$ 3$ billion are spent in Japan alone.

\section{CONCLUSIONS}

The prevalence of chronic allergic respiratory diseases such as asthma and allergic rhinitis is increasing in the AsiaPacific region. With the projected increase in the Asian population over the next decade, the burden of allergic diseases is expected to increase markedly. The exact mechanisms and determining factors underlying the increase in prevalence remain unclear, although allergen sensitization has been found to be at least as common in the region as in the West. Better identification of triggers and risk factors, increased surveillance of the burden of disease, better public awareness, improved training of physicians and health care personnel, better access to essential drugs, implementation of environmental controls, appropriate management, and implementation of preventive measures ${ }^{26}$ are key to reducing the burden of these diseases in the Asia-Pacific region.

\section{REFERENCES}

1. Bousquet J, Dahl R, Khaltaev N. Global alliance against chronic respiratory diseases. Allergy. 2007;62:216-223.

2. Bousquet J, Van Cauwenberge P, Khaltaev N. For the Aria Workshop Group,World Health Organization. Allergic rhinitis and its impact on asthma. J Allergy Clin Immunol. 2001;108(suppl 1):S147-S334.

3. Asher MI, Montefort S, Björkstén B, Lai CK, Strachan DP, Weiland SK, et al. Worldwide time trends in the prevalence of symptoms of asthma, allergic rhinoconjunctivitis, and eczema in childhood: ISAAC Phases One and Three repeat multicountry cross-sectional surveys. Lancet. 2006;368:733-743.

4. Janson C, Anto J, Burney P, Chinn S, de Marco R, Heinrich J, et al. The European Community Respiratory Health Survey: what are the main results so far? European Community Respiratory Health Survey II. Eur Respir J. 2001;18:598-611.

5. Leynaert B, Neukirch C, Liard R, Bousquet J, Neukirch F. Quality of life in allergic rhinitis and asthma. A population-based study of young adults. Am J Respir Crit Care Med. 2000;162:1391-1396.

6. Guerra S, Sherrill DL, Martinez FD, Barbee RA. Rhinitis as an independent risk factor for adult-onset asthma. J Allergy Clin Immunol. 2002;109:419-425.

7. Björkstén B, Clayton T, Ellwood P, Stewart A, Strachan D. For the Phase III Study Group II. World time trends for symptoms of rhinitis and conjunctivitis: phase III of the International Study of Asthma and Allergies in Childhood. Pediatr Allergy Immunol. 2008;19: 110-124.

8. Pearce N, Aït-Khaled N, Beasley R, Mallol J, Keil U, Mitchell E, et al. For the ISAAC Phase Three Study Group. Worldwide trends in the prevalence of asthma symptoms: phase III of the International Study of Asthma and Allergies in Childhood (ISAAC). Thorax. 2007;62: 758-766.

9. Nishima S. A study on the prevalence of bronchial asthma in school children in western districts of Japan - comparison between the studies in 1982 and in 1992 with the same methods and same districts. Arerugi. 1993;42:192-204.

10. Hsieh KE, Shen JJ. Prevalence of childhood asthma in Taipei, Taiwan and other Asian Pacific countries. J Asthma. 1988;25:73-82.

11. Chiang LC, Chen YH, Hsueh KC, Huang JL. Prevalence and severity of symptoms of asthma, allergic rhinitis, and eczema in 10 to 15-year-old schoolchildren in central Taiwan. Asian Pac J Allergy Immunol. 2007; 25:1-5.

12. Aggarwal AN, Chaudhry K, Chhabra SK, D’Souza GA, Gupta D, Jindal SK, et al. Asthma Epidemiology Study Group. Prevalence and risk factors for bronchial asthma in Indian adults: a multicentre study. Indian J Chest Dis Allied Sci. 2006;48:13-22.
13. Zaman K, Takeuchi H, Md Y, El Arifeen S, Chowdhury HR, Baqui AH et al. Asthma in rural Bangladeshi children. Indian J Pediatr. 2007:74:539-543.

14. Droma Y, Kunii O, Yangzom Y, Shan M, Pingzo L, Song P. Prevalence and severity of asthma and allergies in schoolchildren in Lhasa, Tibet. Clin Exp Allergy. 2007;37:1326-1333.

15. Yeoh SM, Kuo IC, Wang DY, Liam CK, Sam CK, De Bruyne JA, et al Dermatophagoides pteronyssinus and Blomia tropicalis. Sensitization profiles of Malaysian and Singaporean subjects to allergens. Int Arch Allergy Immunol. 2003;132:215-220.

16. Leung R, Ho P. Asthma, allergy, and atopy in three south-east Asian populations. Thorax. 1994;49:1205-1210.

17. Daengsuwan T, Lee BW, Visitsuntorn N, Charoenratanakul S, Ruangrak S, Jirapongsananuruk $\mathrm{O}$, et al. Allergen sensitization to aeroallergens including Blomia tropicalis among adult and childhood asthmatics in Thailand. Asian Pac J Allergy Immunol. 2003;21: 199-204.

18. Tan TN, Shek LP, Goh DY, Chew FT, Lee BW. Prevalence of asthma and comorbid allergy symptoms in Singaporean preschoolers. Asian Pac J Allergy Immunol. 2006;24:175-182.

19. World Health Organization. The World Health Report 2004: Changing History. Geneva, Switzerland: World Health Organization; 2004.

20. Zainudin BM, Lai CK, Soriano JB, Jia-Horng W, De Guia TS, For the Asthma Insights and Reality in Asia-Pacific (AIRIAP) Steering Committee. Asthma control in adults in Asia-Pacific. Respirology. 2005;10:579-586.

21. Valovirta E, Pawankar R. Survey on the impact of comorbid allergic rhinitis in patients with asthma. BMC Pulm Med. 2006;30(suppl 1):S3.

22. The Global Initiative for Asthma. Available at: http://www.ginasthma. com. Accessed April 24, 2008.

23. Haahtela T, Klaukka T, Koskela K, Erhola M, Laitinen LA. For the Working Group of the Asthma Programme in Finland 1994-2004. Asthma programme in Finland: a community problem needs community solutions. Thorax. 2001;56:806-814.

24. Lai CKW, Kim Y-Y, Kuo S-H, Spencer M, Williams AE. Asthma Insight and Reality in Asia Pacific Steering Committee. Cost of asthma in the Asia-Pacific region. Eur Respir Rev. 2006;98:10-16.

25. Bateman ED. The economic burden of uncontrolled asthma across Europe and the Asia-Pacific region: can we afford to not control asthma? Eur Respir Rev. 2006;15:1-3.

26. Weiss K, Haus M, Likura Y. The costs of allergy and asthma and the potential benefit of prevention strategies. In: Johansson SGO, Haahtela T, eds. Prevention of allergy and allergic asthma. World Allergy Organization report and guidelines. Chemical Immunology and Allergy, vol 84. Basel, Switzerland: Karger; 2004:184-192.

\section{THE WORLDWIDE INCREASE IN ALLERGY AND ASTHMA}

The global prevalence of asthma and the morbidity, mortality, and economic burden associated with it have increased sharply over the past 40 years, particularly in children. The prevalence of asthma has increased by $50 \%$ every decade. In North America, an estimated 22.2 million persons (6.5 million children and 15.7 million adults) have asthma, and in 2003, asthma accounted for 1.4 deaths per 100,000 persons. ${ }^{1}$ Asthma is underdiagnosed and undertreated, although the use of inhaled corticosteroids has had a positive impact on outcomes.

The increasing number of hospital admissions for asthma, which are most pronounced in young children, reflects an increase in asthma severity in part because of poor disease management. Worldwide, approximately 250,000 deaths per year are attributable to asthma, although overall mortality rates have decreased since the 1980s. Most asthma deaths occur in those aged 45 years and older and are largely preventable. Death is frequently related to inadequate long-term medical 
care (including the lack of affordability in low-income groups) or to delays in obtaining medical help during an attack. ${ }^{2}$

The financial burden related to asthma in different western countries ranges from US $\$ 300$ to US $\$ 1300$ per patient per year and disproportionately affects those with the most severe disease. ${ }^{3}$ The burden in weaker economies is even greater. Several significant barriers exist to reducing the burden of asthma, particularly in low-income groups, in whom access to care and essential medications is limited.

Contrary to the global increases seen in recent decades, some reports have shown no change in asthma trends over the past decade. Such discrepancies exist even among studies from the same country. In addition to differences in methods and the age distribution of the population studied, differences in the degree of urbanization and in the occurrence and magnitude of protective (yet only partially identified) factors among the study areas may explain these discrepancies. Furthermore, geoclimatic variables and topographic factors, for example, the altitude at which people live, may also affect the prevalence of asthma.

Accumulating evidence from some countries, particularly developed countries, indicates that the rising trends in asthma prevalence among adults may now have plateaued or even decreased. The data are more contradictory in children. Several studies have shown stable trends in childhood asthma since the late 1990s, whereas others have not shown any change in the steadily rising asthma trends. In contrast, an upward trend in the prevalence of asthma has been described in those countries with a previously low prevalence, mainly in developing countries. ${ }^{4}$ However, nearly all of these studies lack the most recent data from the 2000s. Moreover, environmental and lifestyle factors may continue to induce asthma symptoms in susceptible persons until the saturation level in prevalence, determined by the genetic composition of the population, is achieved. Defects in environmental Th1 triggering and in inborn Th1 maturation are examples of the environment- and gene-associated factors that might influence asthma prevalence. ${ }^{5}$ However, severalfold higher peak prevalence rates have been reported in Australia, and no peak prevalence rates have yet been reported in many countries with high rates of asthma. Because nearly all the studies referred to here were conducted in affluent westernized countries, no consideration of the results in light of the East-West gradient could be performed. It remains to be determined whether the increased use of antibiotics is involved in the stabilization or decrease observed, particularly in the prevalence of nonimmunoglobulin E (IgE)-mediated (sometimes termed nonatopic) adult asthma, for which an infectious etiology has been proposed. $^{6}$ The results of long-term follow-up, derived from large multinational surveys, including the European Community Respiratory Health Survey and International Study of Asthma and Allergies in Childhood (ISAAC), will be a good indicator of current asthma trends on a global scale.

The Global Initiative for Asthma ${ }^{7}$ has outlined a 6-point patient management plan to address the effective handling of the increased number of asthma patients receiving primary care. The plan focuses on patient education, written treatment plans, and ongoing communication and review between patients and health care providers. Although the asthma pre- vention and management programs have undoubtedly contributed favorably to the reduction in asthma prevalence in many countries, the possibility that asthma has become milder, independently of the increased use of inhaled corticosteroids, cannot be excluded. Furthermore, few studies have analyzed time trends in the prevalence of IgE-mediated and non-IgE-mediated asthma separately. Limited data from the United Kingdom and Finland indicate that the prevalence of IgE-mediated allergic asthma has continued to increase over the past few decades, whereas that of non-IgE-mediated asthma has not. This may indicate that the proportions of IgE-mediated and non-IgE-mediated asthma within the overall asthma burden are also changing, which may additionally explain the finding that asthma has become milder. In the Finnish young male population, the prevalence of asthma increased from $0.29 \%$ in 1966 to $1.79 \%$ in $1989 .{ }^{8}$ In the United Kingdom, an evaluation of the prevalence of asthma in schoolchildren between 1991 and 2002 showed a significant increase in wheezing in the past 12 months and in severe speech-limiting episodes and night waking, but no significant increase in medical visits because of wheezing. ${ }^{9}$ Another time trend study also showed a significant increase in physician-diagnosed asthma from 1990 to 2003, which was more evident in females (range, $7.3 \%-14.6 \%$ ) than in males (range, $7.8 \%-9.4 \%$ ) in all age groups, particularly in persons aged 55 years and older. ${ }^{10}$

\section{PREVALENCE OF ALLERGY AND ASTHMA IN LOW- AND MIDDLE-INCOME COUNTRIES}

In a study that compared the prevalence of asthma and atopy between children from affluent countries and children from nonaffluent countries, the prevalence of wheezing and persistent cough was lower in Nigeria than in Australia (10.2\% and $5.1 \%$ compared with $21.9 \%$ and $9.6 \%$, respectively). ${ }^{11} \mathrm{~A}$ recent report from Ait-Khaled et $\mathrm{al}^{12}$ showed a wide range of atopic disorders that were prevalent throughout Africa, with the highest prevalence of current asthma in urban areas with a higher standard of living (in agreement with the hygiene hypothesis). However, the prevalence of asthma was also high in endemic parasite and tuberculosis zones (in opposition to the hygiene hypothesis). ${ }^{12}$ In Latin America, the prevalence of asthma and allergic diseases in childhood was similar to that in industrialized countries, although the variability was great. ${ }^{13}$ In a recent survey conducted in Asia, the prevalence of wheezing in rural children from Bangladesh over the previous 12 months was $16 \%$, which was not significantly different from the prevalence observed in other developing regions. ${ }^{14}$ Taken together, the evidence shows that the prevalence of asthma is high and is still increasing slightly, mainly in developing countries.

\section{OVERCOMING BARRIERS: A GLOBAL PERSPECTIVE WITH EMPHASIS ON ISAAC}

The ISAAC is a unique global epidemiological study of the prevalence and severity of asthma, rhinitis, and eczema, ${ }^{15}$ although other studies of trends in the prevalence of symptoms of asthma, allergic rhinoconjunctivitis and eczema in children 
and adolescents have used similar methods. In the counties of Troms and Finnmark in Norway, divergent trends in symptom prevalence were observed. Investigators reported no change in the prevalence of symptoms of asthma, hay fever, or eczema in centers in eastern and southwestern Germany, whereas other investigators reported an increase in the prevalence of hay fever symptoms, but not that of asthma or eczema, in East Germany. In Ankara, Turkey, a significant decrease in the cumulative prevalence of allergic rhinitis was noted, with a slight insignificant increase in the prevalence of asthma and eczema. Tallinn in Estonia was the only center included in the present study for which trends for asthma, allergic rhinoconjunctivitis, and eczema had been studied previously. Little change was reported in the prevalence of wheezing, rhinitis, and itching rash between cross-sectional studies completed in 1992-1993 and 1996-1997. In Aberdeen, United Kingdom, the prevalence of asthma symptoms plateaued, ${ }^{16}$ whereas the prevalence of eczema and hay fever symptoms increased.

The data on trends in symptoms of asthma, allergic rhinoconjunctivitis, and eczema have direct relevance to health service delivery in the countries included in the studies and provide a basis for understanding these disorders. In almost all participating centers, the prevalence of one or more of the disorders changed over time. Although changes in the mean annual prevalence of approximately $0.5 \%$ might sound small, such changes could have substantial public health implications, especially because the increases took place primarily in heavily populated countries. Urban centers in developing countries might have few resources to implement management programs for these diseases in the face of an overwhelming number of infectious diseases. The level of interest from centers in developing countries participating in prevalence studies indicates a concern that asthma and allergies in children are emerging as important public health problems. ${ }^{4}$

The ISAAC has provided valuable data on the prevalence and severity of asthma, rhinitis, and eczema. The prevalence of asthma is highest in English-speaking countries, and little variation exists within English-speaking countries. The overall prevalence is higher than expected, particularly in Latin America. However, variation exists among and within countries; for example, there is a northwest-southwest gradient within Europe. The correlation between asthma prevalence and the gross national product is inconsistent. In some areas (eg, Germany and China), a major difference in prevalence exists within the same ethnic group, and a weak and inconsistent association exists between the prevalence of asthma and that of other allergic conditions. The ISAAC phase III data suggest an upward trend in the prevalence of asthma in Argentina. In Cordoba, the only center that participated in both phases I and III, the prevalence increased from $11.2 \%$ to $11.6 \%$.

In conclusion, prevalence studies, such as ISAAC, that take into account differentials in variables such as poverty, population, immigration patterns, and ethnic and cultural differences are a major step toward overcoming existing barriers to the worldwide diagnosis and treatment of asthma.

\section{REFERENCES}

1. National Center for Health Statistics. Asthma prevalence, health care use and mortality: United States, 2003-2005. Available at: http://www.cdc. gov/nchs/products/pubs/pubd/hestats/ashtma03-05/asthma03-05.htm\#1. Accessed October 2007

2. Masoli M, Fabian D, Holt S, Beasley R. Global Initiative for Asthma (GINA) Program. The global burden of asthma: executive summary of the GINA Dissemination Committee report. Allergy. 2004;59: 469-478.

3. Accordini S, Corsico A, Cerveri I, Gislason D, Gulsvik A, Janson C, et al. Therapy and Health Economics Working Group of the European Community Respiratory Health Survey II. The socio-economic burden of asthma is substantial in Europe. Allergy. 2008;63:116-124.

4. Asher MI, Montefort S, Björkstén B, Lai CK, Strachan DP, Weiland SK, et al. ISAAC Phase Three Study Group. Worldwide time trends in the prevalence of symptoms of asthma, allergic rhinoconjunctivitis, and eczema in childhood: ISAAC Phases One and Three repeat multicountry cross-sectional surveys. Lancet. 2006;368:733-743.

5. Romagnani S. Regulatory T cells: which role in the pathogenesis and treatment of allergic disorders? Allergy. 2006;61:3-14.

6. von Mutius E. Of attraction and rejection - asthma and the microbial world. $N$ Engl J Med. 2007;357:1545-1547.

7. The Global Initiative for Asthma. Available at: http://www.ginasthma com. Accessed April 24, 2008.

8. von Hertzen L, Haahtela T. Signs of reversing trends in prevalence of asthma. Allergy. 2005;60:283-292.

9. Butland BK, Strachan DP, Crawley-Boevey EE, Anderson HR. Childhood asthma in South London: trends in prevalence and use of medical services. Thorax. 2006;61:383-387.

10. Wilson DH, Adams RJ, Tucker G, Appleton S, Taylor AW, Ruffin RE. Trends in asthma prevalence and population changes in South Australia, 1990-2003. Med J Aust. 2006;184:226-229.

11. Faniran AO, Peat JK, Woolcock AJ. Prevalence of atopy, asthma symptoms and diagnosis, and the management of asthma: comparison of an affluent and a non-affluent country. Thorax. 1999;54:606-610.

12. Ait-Khaled N, Odhiambo J, Pearce N, Adjoh KS, Maesano IA, Benhabyles B, et al. Prevalence of symptoms of asthma, rhinitis and eczema in 13- to 14-year-old children in Africa: the International Study of Asthma and Allergies in Childhood Phase III. Allergy. 2007;62: 247-258.

13. Mallol J, Solé D, Asher I, Clayton T, Stein R, Soto-Quiroz M. Prevalence of asthma symptoms in Latin America: the International Study of Asthma and Allergies in Childhood (ISAAC). Pediatr Pulmonol. 2000;30: 439-444.

14. Zaman K, Takeuchi H, Md Y, El Arifeen S, Chowdhury HR, Baqui AH, et al. Asthma in rural Bangladeshi children. Indian J Pediatr. 2007;74: 539-543.

15. ISAAC Home. Available at: http://isaac.auckland.ac.nz/. Accessed April 24, 2008.

16. Ninan TK, Russell G. Respiratory symptoms and atopy in Aberdeen schoolchildren: evidence from two surveys 25 years apart. BMJ. 1992; 304:873-875.

\section{HOW ORGANIZATIONS ARE RESPONDING TO THE GLOBAL INCREASE IN ALLERGIC RESPIRATORY DISEASE}

The incidence of chronic allergic respiratory diseases is increasing, and a united effort across nations and organizations is needed to address effectively this global concern.

\section{THE GLOBAL ALLIANCE AGAINST CHRONIC RESPIRATORY DISEASES}

The Global Alliance against Chronic Respiratory Diseases (GARD) is a voluntary alliance of 70 national and international organizations, institutions, and agencies working toward the common goal of reducing the incidence of chronic respiratory diseases worldwide, according to local needs. ${ }^{1}$ The GARD's vision is "a world where all people breathe freely." The key aim of GARD is to initiate a comprehensive approach 
to fighting chronic respiratory diseases. The GARD was created in recognition of the impact that chronic respiratory diseases have on the global community. Many chronic respiratory diseases, including asthma and rhinitis, are increasing in prevalence, even though these diseases are allergic in origin and are therefore preventable.

The 53rd World Health Assembly recognized the enormous human suffering caused by chronic diseases and requested the Director General of the World Health Organization (WHO) to give priority to the prevention and control of these diseases (WHO resolution 53.17, May 2000; endorsed by all 191 WHO Member States). This led to the formation of GARD.

The GARD is being developed in a stepwise approach using three planning steps that follow the steps outlined in "Preventing Chronic Disease: A Vital Investment," a report issued by the WHO. To pursue the vision of "a world where all people breathe freely," GARD's mission is to develop an environment that enables sustainable appropriate action at individual, community, national, and global levels. The goal of all GARD's actions is to reduce the chronic respiratory disease burden globally. ${ }^{3}$

The GARD's specific objectives include the following:

- Developing a standard way of obtaining relevant data on the risk factors for and disease burden of chronic respiratory diseases.

- Advocating policies that promote health and disease prevention in countries worldwide.

- Developing simple and affordable strategies for the diagnosis and management of chronic respiratory diseases in all countries.

- Adapting and tailoring all recommendations to each country's health priorities, health care system, diversity of chronic respiratory diseases, availability of health care personnel, facilities for diagnosis, and availability and affordability of medications.

In addition, GARD aims to improve coordination between existing governmental and nongovernmental programs and to avoid duplication of effort and wastefulness of resources. Such coordination will also enable participant organizations to work synergistically to achieve GARD's objectives.

\section{GARD WORKING GROUPS}

Following a model of collaboration and coordinated activity, GARD and the World Allergy Organization (WAO) are working together through established GARD working groups on major programs in the following four areas: prevention, diagnostics, management, and pediatrics.

\section{Working Group on Health Promotion and Prevention of Chronic Respiratory Disease and Allergies}

Everyone has the right to live and work in a clean environment. Exposure to an unhealthy environment can cause severe and debilitating chronic obstructive pulmonary disease, asthma, cardiovascular diseases, and cancer. Complete elimination of risk factors is the only way to remove the risk, and this strategy applies equally to tobacco smoke, indoor and outdoor air pollutants, occupational hazards, and allergens. This working group will encourage countries to implement policies to reduce the burden of tobacco smoke, indoor and outdoor pollution, occupational hazards and other risk factors relevant to chronic respiratory disease.

\section{Working Group on Diagnosis of Chronic Respiratory Disease and Allergies}

The first initiative for the Diagnostics Working Group is to survey WAO Member Societies (national and regional allergy and clinical immunology societies worldwide) to define the most relevant allergens in each country. This will enable the group to ensure the development of low-cost tests for immunoglobulin E sensitization against the most common respiratory and food allergens in any country or region. A second survey was created to obtain information about which in vivo and in vitro tests are most commonly used worldwide to detect respiratory, food, and drug allergies.

The Diagnostics Working Group will also conduct allergy skin prick tests for immunoglobulin E sensitization using either standardized manufactured allergens (in high- and middle-income countries) or locally produced reliable extracts (in middle- and low-income countries). Central to this is the detection of relevant regional allergens, done in cooperation with the WAO Emerging Societies Program (see Developing the Specialty of Allergy Worldwide), which has placed pollen traps in countries where major airborne allergens need to be identified.

\section{Working Group on Control of Chronic Respiratory Disease and Allergies}

The GARD action plans should be tailored to each country's needs, priorities, health services, and resources.

- In areas with a high burden of communicable diseases and a functioning primary health care service, an integrated approach to prevention, diagnosis, and management is recommended. Models such as the WHO-Practical Approach to Lung Health will be promoted.

- In areas with a high prevalence of human immunodeficiency virus infection, models such as PALSA Plus (PAL in South Africa) will be promoted.

- Prevention and care for chronic respiratory disease in middle- and high-income countries may involve the use of different models. Disease-specific approaches can be more relevant and might target asthma, rhinitis, chronic obstructive pulmonary disease, and occupational lung diseases. Approaches will be developed from available management plans and international guidelines according to countryspecific needs.

\section{Working Group on Pediatric Chronic Respiratory Disease and Allergies}

Approximately $70 \%$ to $80 \%$ of asthma in children is allergic in origin, and $5 \%$ to $15 \%$ of the global pediatric population is thought to have asthma. ${ }^{4}$ The Pediatrics Working Group believes that future increases in asthma prevalence will 
likely be greatest in the developing world. The group has outlined objectives for the diagnosis and management of pediatric asthma in high-, middle-, and low-income countries. The priorities are to develop an asthma-symptom algorithm to aid health care practitioners in making diagnoses and to provide "Is it asthma?" symptom cards, developed by GARD, to facilitate such diagnoses. Pamphlets and posters will also be developed to increase awareness about asthma. Emphasis will continue to be placed on the importance of avoiding tobacco smoke. Finally, prevalence studies will be conducted in preschool children.

\section{THE WORLD ALLERGY ORGANIZATON}

The WAO is an international umbrella organization with a membership consisting of 77 regional and national allergology and clinical immunology societies from around the world. 5 The WAO is a founding member of GARD and is also one of GARD's most active and supportive members. The WAO's approach is complementary to that of GARD: to fight allergic diseases worldwide. The WAO is in a unique position to synthesize the best allergy practices developed by longestablished allergy societies, to disseminate the knowledge gained throughout diverse geographic regions, and to share relevant experiences with newer allergy and clinical immunology societies and allergists worldwide. In collaboration with WAO's member societies, WAO provides direct educational outreach programs, specialty development programs, symposia, and lectureships to members in 92 countries. Chronic allergic respiratory disease, which encompasses allergic asthma, rhinoconjunctivitis, and sinusitis, is a natural focus of interest for WAO members and thus was selected as the focus of the joint WAO/GARD World Allergy Day 2007.

\section{DEFINING THE SPECIALTY OF ALLERGY AND THE NEED FOR ALLERGY SERVICES}

No studies that provide a complete picture of the size of the global allergy epidemic have been reported. Figures available from peer-reviewed studies provide only limited snapshots of the prevalence of particular allergic diseases in specific population subgroups at the time of sampling. In 2005, the WAO Specialty and Training Council conducted an informal survey of WAO member societies and requested estimates of the proportion of the population in each country with allergic disease and estimates of the resources available to manage these patients. The results, published in $2006,{ }^{6}$ included responses from member societies representing 33 countries and suggested that approximately 16,000 trained allergists serve an estimated total population of 1.3 billion persons, approximately $22 \%$ of whom have some form of allergic disease. The survey confirmed that most allergy patients are not seen by a trained allergist; therefore, these patients may not be receiving optimal care. A formal follow-up survey requested information on the documented prevalence of asthma, allergic rhinitis, atopic eczema, food allergy, drug allergy, and Hymenoptera allergy, ${ }^{7}$ and provides a clearer picture of the global incidence of specific allergic diseases. Studies of anaphylaxis prevalence and anaphylaxis manage- ment practices are in progress and will be based on international surveys being conducted by WAO member societies over the 3-year period from 2007 to 2009.

The findings from the Allergy Practice Worldwide Survey guided the development of a WAO position statement, "Requirements for Physician Competencies in Allergy: Key Clinical Competencies Appropriate for the Care of Patients with Allergic or Immunologic Diseases-A Position Statement of the World Allergy Organization." 8 This statement provides advice for the development of allergy specialist programs and recommends that appropriately targeted educational programs be developed for the thousands of nonallergists worldwide who treat allergy patients.

The new WAO position statement, "What Is an Allergist?" was published in The World Allergy Organization Journal in January 2008. 9 This position statement outlines what patients and health care providers should expect from allergy specialists and aims to help physicians refer patients appropriately to allergists. Further statements on recommendations for training on allergies, at both the undergraduate level and for pediatric allergists, will be developed during 2008. The WAO position statements have been created to establish and strengthen the specialty of allergy and to convince governments and health care systems of the importance of providing and supporting allergy services.

\section{DEVELOPING THE SPECIALTY OF ALLERGY WORLDWIDE}

\section{The WAO Emerging Societies Program}

The WAO Emerging Societies Program encourages the development of new national allergy societies throughout the world, particularly in low-income countries. The program is provided in collaboration with the American College of Allergy, Asthma, and Immunology. While enabling the sharing of practical experiences and alerting aspiring societies to the criteria required for WAO membership, the program helps to create local support networks for allergists through partnerships with established allergy societies within the same region and fosters a relationship with WAO. At the same time, the WAO leadership learns about the challenges and opportunities faced by colleagues in developing countries. Membership in WAO enables fledgling societies to become a part of the global allergy community and to have a voice in WAO's House of Delegates, where the societies can help to determine the organization's future activities.

The WAO is planning a network of local summer schools that will provide hands-on training in allergy diagnostic techniques and methods of treatment delivery in areas where allergy services are newly established. In 2008, the Emerging Societies Program will hold a summer school for primary care physicians in Latin America, an area where allergy services are deficient. The summer school will provide training in the fundamentals of allergy diagnosis and treatment.

The Emerging Societies Program has loaned pollen traps to centers in Pakistan, Ukraine, and Georgia. These traps are helping allergists identify the major local airborne pollens and molds responsible for allergic respiratory diseases in these countries, and the hope is that the information acquired will 
eventually lead to the availability of appropriately directed diagnostic materials and immunotherapy vaccines. The distribution of more pollen traps is an urgent priority.

\section{Allergy Learning and Educational Programs}

The WAO offers a variety of educational and learning programs that reflect the diversity of learning needs within the global allergy environment. The Global Resources in Allergy (GLORIA) program provides educational materials in the form of didactic lectures on major topics in allergy; these lectures are available on the WAO Web site so that the organization's 35,000 members can use the GLORIA materials in teaching programs. ${ }^{10}$ The Seminars and Conferences Program provides invited lecturers to speak at member societies' meetings on topics selected to specifically meet the learning needs of the societies' local clinical and scientific allergy community. In 2007, WAO provided lectures on various aspects of allergy to more than 25 allergy and clinical immunology societies throughout the world and will provide even more in 2008.

To further improve education worldwide, WAO has just created an online clinical journal, The World Allergy Organization Journal, to be a major academic resource for the world's allergy community. ${ }^{11}$

Focusing on the knowledge objectives for physicians as defined by the Specialty and Training Council, ${ }^{8}$ WAO is also developing learning programs aimed at meeting the learning needs of the diverse range of physicians who care for patients with allergic diseases. A major strategy of this goal is online education, which is increasingly accessible worldwide and is a cost-effective way of providing learning and educational materials asynchronously at a convenient time for global users. New initiatives for 2008 include a series of 11 online lectures on the basic immunology underlying allergic disease and a series of online learning programs based on complex clinical case histories, through which users are guided through the wealth of educational materials that are available on the WAO Web site.

\section{Promoting Allergy Research}

The WAO Research Council awards annual short- and long-term research fellowships enabling junior clinicians to visit an international expert center to learn a clinical or scientific technique that is not available at the home institution or to participate in a research study. These programs aim to help the students' home institutions establish new research programs, and particular emphasis is given to encouraging research in low-income countries. Fellowships are directed toward three broad research priorities:

- Genetic factors involved in the development of allergic disease and response to treatment;

- Allergen characterization and standardization; and

- Clinical and basic studies in allergy and asthma.

\section{Best-Practice Recommendations and Position Statements}

The WAO collaborated with the WHO to develop recommendations for the prevention of allergy and allergic asthma based on the recommendations of a group of international allergy experts representing all WHO regions. The document, published in 2004, summarized current knowledge on the prevention of allergy and allergy-related asthma and made recommendations for future research to address knowledge gaps. ${ }^{4}$

The WAO Research Council oversees the creation of position statements on major topics in allergy. "Recommendations for Standardization of Clinical Trials With Allergen Specific Immunotherapy for Respiratory Allergy: A Statement of a World Allergy Organization Taskforce" was published in 2007 to ensure that new clinical trials on allergen immunotherapy are conducted in a standardized way that will enable worldwide comparability of results. ${ }^{12}$

The WAO is conducting studies on the current availability of epinephrine and on the local management of anaphylaxis in all member society countries. In parallel with these studies, the organization is developing global recommendations on the use of epinephrine for the treatment of anaphylaxis. Although epinephrine is the drug of choice for the treatment of anaphylaxis, this drug is not yet globally available. The hope is that WAO initiatives will assist national societies in persuading health care funding bodies of the importance of making epinephrine widely available for the treatment of anaphylaxis.

\section{Communication}

The WAO Web site (www.worldallergy.org) is a major tool for disseminating education and information. A monthly e-newsletter reaches more than 26,000 allergists and is available in eight languages. The newsletter provides reviews on current scientific literature and books, updates on WAO activities, and opportunities for member societies to apply for educational programs and fellowships. The WAO Web site contains extensive educational resources and contact information and provides links to all WAO member societies' Web sites and selected allergy resources on the World Wide Web.

World Allergy Day takes place every two years and is themed on activities at the biennial World Allergy Congress. This event provides an opportunity for wider dissemination of knowledge on major topics in allergic disease, with participating member societies, local media, and patient groups focusing on those aspects of allergic disease that have the greatest impact on local communities.

All WAO resources and services are designed to increase the knowledge and awareness of allergic disease and enhance the clinical practice of allergy. The WAO's role is to support member societies in promoting the specialty at a national level and to provide information to help in negotiations to obtain optimal resources for the care of allergy patients. Thus, development of the specialty of allergy, physician education and information, best-practice recommendations, promotion of allergy research, and creation of an awareness of the global allergy burden are critical responsibilities of WAO. Because of the enormous global burden of allergic disease, most patients with allergy will not be seen by an allergist; therefore, nonallergists must be educated to recognize, diagnose, and treat patients with uncomplicated allergy and to know when and how to refer patients with complex disease to an allergist. 


\section{SUMMARY}

At a global level, governments and those who fund health care must be informed about the burgeoning prevalence of allergic disorders and the likelihood that patient numbers will continue to increase. Collaboration between GARD and WAO is of major importance to both organizations in fighting the global problem of chronic allergic respiratory diseases.

\section{REFERENCES}

1. World Health Organization. Global Alliance Against Chronic Respiratory Diseases Web site. Available at: http://www.who.int/gard. Accessed April 24, 2008.

2. Bousquet J, Dahl R, Khaltaev N. Global alliance against chronic respiratory diseases. Allergy. 2007;62:216-223.

3. Bousquet J, Khaltaev N. Global surveillance, prevention and control of chronic respiratory siseases. A comprehensive approach. Geneva, Switzerland: Global Alliance Against Chronic Respiratory Diseases, World Health Organization; 2007.

4. Johansson SGO, Haahtela T. Prevention of allergy and allergic asthma. In: Ring J, et al, eds. Chemical immunology and allergy, vol 84. Basel, Switzerland: Karger; 2004. Summary available at: http://www. worldallergy.org/professional/who_paa2003.pdf. Accessed April 23, 2008.

5. World Allergy Organization Web site. Available at: http://www. worldallergy.org. Accessed April 24, 2008.

6. Warner JO, Kaliner MA, Crisci CD, Del Giacco S, Frew AJ, Gh L, et al. Allergy practice worldwide: a report by the World Allergy Organization Specialty and Training Council. Allergy Clin Immunol Int-J World Allergy Org. 2006;18:4-10; and Int Arch Allergy Immunol. 2006;139:166-174.

7. Compalati E, Penagos M, Henley K, Canonica GW. Allergy prevalence survey by the World Allergy Organization. Allergy Clin Immunol Int- J World Allergy Org. 2007;19:82-90.

8. Kaliner MA, Del Giacco S, Crisci CD, Frew AJ, Liu G, Maspero J, et al; for the WAO Specialty and Training Council. Requirements for physician competencies in allergy: key clinical competencies appropriate for the care of patients with allergic or immunologic diseases - a position statement of the World Allergy Organization. World Allergy Organization $J$ [serial online]. 2008;1:42-46. Available at: www.waojournal.org. Accessed April 30, 2008

9. Del Giacco S, Rosenwasser LJ, Crisci CD, Frew AJ, Kaliner MA, Lee B-W, et al. What is an allergist? A position statement of the WAO Specialty and Training Council. World Allergy Organization J [serial online]. 2008;1:19-20. Available at: www.waojournal.org. Accessed April 30, 2008.

10. World Allergy Organization. GLORIA presentation materials. Available at: http://www.worldallergy.org/educational_programs/gloria/ international/materials.php. Accessed April 24, 2008.

11. World Allergy Organization Journal. Home. Available at: waojournal.org Accessed April 24, 2008.

12. Canonica GW, Baena-Cagnani CE, Bousquet J, Bousquet PJ, Lockey RF, et al. Recommendations for standardization of clinical trials with allergen specific immunotherapy for respiratory allergy: a statement of a World Allergy Organization taskforce. Allergy. 2007; $62: 317-324$

\section{FUTURE TRENDS IN ALLERGY PREVALENCE AND TREATMENT: WHAT TO EXPECT?}

This section contains a bibliography of general references. Further resources and references are provided through links from the reference list to WAO's online learning materials.

How will environmental and social changes influence the prevalence of allergic diseases in the global population, and how will the world need to respond?

\section{FACTORS AFFECTING ALLERGY PREVALENCE AND TREATMENT}

Although the future is difficult to predict, one thing is certain: change is the only "constant." Several factors will affect the future prevalence and treatment of allergy, including climate change, an increase in industrialization, and the resultant increase in exposure to allergens. A consequence of the anticipated increase in allergic diseases is that the present inadequacy in the training of physicians in the diagnosis and treatment of allergy and asthma must be addressed.

\section{Climate Change}

Recently, much attention has focused on climate change and the impact of climate on allergy. Experts from the World Health Organization discussed the impact of climate on allergy in May 2007, and numerous articles on this topic have appeared in the literature and on the Internet. ${ }^{1-19}$ Climate affects many aspects of allergy and allergen exposure, including the type and frequency of allergens in any particular geographic location, exposure to food and insect allergens, cross-reactivity among allergens, and the prevalence of allergy-related diseases.

The world is in the initial stages of a global climate change that will alter flora and fauna everywhere, creating changes in the profile of local allergens and potentially lengthening pollen allergy seasons. As temperatures increase, plant species are moving into previously temperate regions and to higher elevations; similarly, when temperatures decrease, these same plant species may recede back to the original habitat, whereas other plant species that typically grow only in colder locales or at higher elevations may spread farther into previously warmer areas. As warm seasons lengthen, so will many plant pollination seasons; therefore, human exposure to allergenic pollens will increase. Increases in temperature will result in increases in humidity in many places, which in turn will provide a better environment for mold growth and an increase in the number of airborne mold spores. Increases in temperature in desert regions are reducing the amount of fertile land available for agriculture, which leads to the migration of large numbers of workers into urban areas. This rural to urban migration has already been shown to result in an increase in the number of patients with asthma and allergy symptoms. Changes in climate will affect crop patterns and increase the likelihood of new inhalant allergens being introduced into a locality. In addition, insect species will continue to migrate to new locations as temperatures increase. Allergies to stinging insects may increase as new insects are introduced into the environment, and the number of cockroaches and house-dust mites - and thus, the allergen load-will increase in accordance with increases in heat and humidity.

Cross-reactivity of allergens currently in the environment with new allergens that are introduced through plant and insect migration could result in the development of multiple immunoglobulin $\mathrm{E}$ (IgE) antibodies against these allergens. This in turn will cause patients to react to more allergens, increase the number of allergy patients, and lead to the development of more complex manifestations of allergic disease.

Although attempts to reduce pollution are gaining importance in some parts of the world, pollution is dramatically 
increasing in other developing areas. To confound this issue, measures aimed at reducing atmospheric pollution will likely result in a decrease in the number of patients with chronic respiratory diseases, such as bronchitis. However, in areas such as the former East Germany, the number of patients with allergy-related respiratory diseases reportedly increased as chronic respiratory diseases decreased.

Allergy has been called "the 21st century disease" because as people live cleaner, healthier, less infection-prone lives, allergies increase in frequency. A theory on how improved hygiene leads to a shift in immune responses favoring an allergic-type response has strong scientific support. Thus, as the world develops to a more industrialized less agriculturally based economy, allergies will continue to increase and plague those very areas where lifestyles are improving.

\section{Dietary Changes Caused by Industrialization}

Allergy clinicians are seeing an epidemic of food allergies in developed countries..$^{20,21} \mathrm{Up}$ to $10 \%$ of children in the United States and Europe will develop food allergies during the first decade of life, with the highest incidence in the first one or two years of life. A reduction in breast-feeding by working mothers has led to an increase in exposure at an early age to foreign proteins such as those in cow's milk. Moreover, these bottle-fed babies are ingesting foreign proteins that would ordinarily be broken down by the mother's digestive and immune system during the formation of breast milk. Greater use of processed foods and preservatives may also increase the exposure to more allergenic proteins. Genetic modification of food can introduce an allergen into a previously "safe" food, rendering the food allergenic to those who are sensitized to the modifying protein.

\section{Decreases in the Number of Trained Physicians for the Projected Increase in Allergy Patients}

Estimates indicate that up to $20 \%$ to $25 \%$ of the population of every developed nation will develop some form of allergic disease. ${ }^{22,23}$ As countries develop more comfortable lifestyles and life-threatening infections are eliminated, allergies not only will continue to increase, but will affect this increasing segment of the population for a lifetime and lead to increased losses in productivity both at school and in the workforce, and thereby result in greater costs to society. With further reductions in breast-feeding and increases in exposure to processed food, food allergies will become more serious and more widespread. Accurate diagnosis and treatment of IgEmediated food allergy will become ever more important. As the Third World moves to the First World and as the prevalence of allergy increases globally, the need for more allergy practitioners and new allergy treatments will increase.

Clearly, there are not enough allergists to diagnose and treat the projected increased number of patients with allergy. ${ }^{24}$ This shortage of appropriately trained health care providers is compounded by the fact that in many highly industrialized countries, the overall rising costs of health care have dictated a reduction in the specialty care provided by allergists, with the expectation that allergy can be treated adequately by family practitioners. Many patients with allergies are treated by physicians who have had an extremely limited exposure to allergy diagnosis and treatment during medical school and postgraduate training.

The WAO, speaking for all 77 allergy and immunology member societies worldwide, has just published two position statements addressing these issues: the first, "What Is an Allergist," 25 defines the special clinical skill sets of a trained allergist; the second, "Requirements for Physician Competencies in Allergy: Key Clinical Competencies Appropriate for the Care of Patients With Allergic or Immunologic Diseases," ${ }^{26}$ delineates exactly what training is required for physicians at all levels to care competently for allergy patients. The WAO Specialty and Training Council is now developing a recommended training syllabus in Allergy and Clinical Immunology to provide a standardized basic curriculum that can be adapted for local use around the world. The hope is that the governing bodies of the world's medical communities will attend to these position statements and not only recognize the current and future deficiencies in the numbers of welltrained allergists, but also encourage specialty training in allergy diagnosis and treatment on a more local level. New WAO initiatives will address the importance of including allergy and clinical immunology in undergraduate medical training and of the special skill sets required for physicians treating children with allergic diseases.

\section{CHANGES IN ALLERGY TREATMENTS}

\section{Antihistamines}

Oral antihistamines have traditionally been the first-line therapy for rhinoconjunctivitis and allergic skin conditions. Histamine is at least partly responsible for most or all of the primary symptoms of allergy, both in the mucosa of the nose and eyes and in the skin. Countless patients worldwide have benefited from the use of oral antihistamines, which reduce sneezing, itching, and rhinorrhea. In recent years, newer nonsedating antihistamines have become available and are recommended because these agents cause less sedation, have more selective mechanisms of action, and are longer lasting. Because oral antihistamines are accepted and are available worldwide, these drugs will likely remain the standard treatment of choice for allergic diseases, and the use of nonsedating antihistamines will likely increase. Nasal antihistamine sprays have also become available more recently and are very effective. In the future, both oral and nasal antihistamines will likely be used to treat rhinitis, and oral antihistamines will likely be used to treat cutaneous disorders. ${ }^{27,28}$

\section{Corticosteroids}

Recognition that topical corticosteroids are the most effective treatments available for rhinitis and asthma should lead to an increase in the use of these drugs for the treatment of these diseases worldwide. Some of the mature corticosteroid products are very inexpensive; therefore, well-trained practitioners can prescribe these modern medicines even in regions where resources are limited.

The WAO anticipates that the emphasis will likely be to use more topical rather than systemic treatments for rhinitis 
and asthma. The combination of topical nasal corticosteroids and antihistamines actually potentiates the activity of each drug in the treatment of rhinitis, and such a combination product, once marketed as a dual-acting nasal spray, is likely be the preferred choice for treating both allergic and nonallergic rhinitis. Surgical treatment of sinusitis will inevitably become less popular as the understanding of this condition increases and effective treatments, including corticosteroids developed in vehicles that allow instillation within the sinuses, become more widely available. ${ }^{29-31}$

Predictably, the medications currently used to treat allergy may not all be used in the future. Many modern medications are cost prohibitive and are therefore unavailable to much of the world. Future advances in pharmaceuticals may provide relatively inexpensive treatments, which will be particularly cost effective if used appropriately by both clinicians and patients.

\section{Immunomodulation}

Modulation of the immune system to decrease the production of $\operatorname{IgE}$, and thereby reduce the incidence of allergic disease, should become a reality. In contrast, immunomodulation to increase the production of IgG might help prevent infectious diseases in patients with IgG deficiencies.

\section{Allergen Immunotherapy}

Allergen immunotherapy has become highly standardized as allergens have become characterized, which ensures an accurate diagnosis and treatment with the specific allergen to which patients are sensitized. ${ }^{32,33}$ Comparative data indicate that allergen immunotherapy is a potent long-term treatment capable of reducing the severity of allergic rhinitis and asthma. Data indicate that the use of immunotherapy to treat children with allergic rhinitis reduces the subsequent development of asthma. Thus, allergen immunotherapy should be considered for the long-term management of appropriately selected allergic patients.

Traditionally, allergen immunotherapy has been administered via subcutaneous injection. Support for this preferred route of administration is based on 100 years of experience and the results of a multitude of studies on the use of high-dose subcutaneous injection therapy. An alternative form of immunotherapy is the sublingual administration of allergen, the effectiveness of which has been demonstrated in European patients with rhinitis caused by certain allergens, such as grass and house-dust mite. Sublingual immunotherapy has become the preferred treatment of some allergic patients in Europe. Studies examining the efficacy of this treatment in other populations are underway. Because sublingual immunotherapy is self-administered, a strong likelihood exists that this therapy will be preferred by patients once proven and approved throughout the world.

Immunotherapy is the only current treatment that has long-term benefits, that is, effects that last beyond the period of active treatment. Studies have clearly shown that effective allergen immunotherapy can have protective effects that last for years after treatment has ended. Thus, immunotherapy can reduce allergic rhinoconjunctivitis and asthma, can reduce the development of asthma in treated patients, can produce effects that last for years after the completion of a successful program, and may become available as sublingual drops for some patents. An increased use of immunotherapy in the future seems likely. However, well-trained practitioners are essential to ensure the accurate identification of the causative allergen or allergens, to determine when sublingual immunotherapy should be used, to ensure patient safety, and to select allergens that are appropriate to the patient.

\section{Biotechnology}

Monoclonal antibodies against IgE and the various cytokines and mediators involved in the allergic cascade are being extensively researched. ${ }^{34-36}$ A humanized monoclonal antibody against $\operatorname{IgE}$ is already available for use in adults and adolescents with moderate to severe allergic asthma and may soon be indicated for use in children. Studies are underway to determine the full range of atopic conditions for which monoclonal anti-IgE therapy may be efficacious. Cost considerations and the availability of trained allergists to determine the patients for whom this type of therapy will be effective will initially determine the global availability of this class of treatments.

\section{Epinephrine}

Anaphylaxis is an acute life-threatening condition that affects about $1 \%$ of the population of most developed countries. More than 200 patients are estimated to die of anaphylaxis in the United States each year. Autoinjected epinephrine (adrenaline) is an extremely effective treatment of acute anaphylaxis because this drug reverses all of the life-threatening processes involved in a matter of minutes. ${ }^{37,38}$ Practitioners in countries where this therapy is licensed can readily provide epinephrine-containing devices to patients at risk for anaphylaxis from stinging insects, food allergies, and other causes of anaphylaxis.

The fact that many countries still do not license epinephrine injectors for prescription purposes is amazing. The WAO's leadership believes that autoinjectors of epinephrine need to become more widely available and that physicians need to be instructed in how and when to use these injectors for the treatment of anaphylaxis. In countries where epinephrine autoinjectors are available, anaphylaxis can be successfully managed by patients who are trained to use these devices correctly. However, epinephrine injectors should be prescribed only by practitioners with the knowledge to: accurately diagnose the symptoms of anaphylaxis, diagnose the causative allergens, advise patients on strategies to avoid the offending allergen, and train patients in the proper use of this life-saving treatment. Recognizing, even in 2007, that self-injectable epinephrine devices are still not available in many countries with huge populations, WAO will continue to campaign for the global availability of this essential therapy.

\section{DISEASE MANAGEMENT GUIDELINES}

As the incidence and importance of asthma and other allergies increase around the world, treatment guidelines developed in conjunction with WAO member societies will 
become even more important. ${ }^{29,39}$ These guidelines will provide a broad framework for treatment that can be used in all communities once suitable treatments become widely available.

\section{CONCLUSIONS}

The prevalence of all types of allergic diseases, such as allergic rhinoconjunctivitis, asthma, sinusitis, food allergies, and anaphylaxis is increasing. Health care resources are not increasing commensurately, and the number of physicians trained to diagnose and treat allergic diseases is insufficient. Resources can be maximized by increasing the number of physicians trained to treat allergic diseases and by implementing and encouraging compliance with guidelines for the treatment of these diseases. The need for new allergy medications, new forms of treatment delivery, and worldwide access to licensed allergy medications is urgent.

\section{REFERENCES}

1. Truong C, Palmé AE, Felber F. Recent invasion of the mountain birch Betula pubescens ssp. tortuosa above the treeline due to climate change genetic and ecological study in northern Sweden. J Evol Biol. 2007; 20:369-380.

2. Confalonieri U, Menne B, Akhtar R, Ebi M, Hauengue RS, Kovats B, et al. Human health. In: Parry ML, Canziani OF, Palutikof JP, van der Linden PJ, Hanson CE, eds. Climate Change 2007: Impacts, Adaptation and Vulnerability. Contribution of Working Group II to the Fourth Assessment Report of the Intergovernmental Panel on Climate Change. Cambridge, UK: Cambridge University Press; 2007:391-431. Available at: http://www.ipcc.ch/ipccreports/ar4-wg2.htm. Accessed February 19, 2008.

3. Wayne P, Foster S, Connolly J, Bazzaz F, Epstein P. Production of allergenic pollen by ragweed (Ambrosia artemisiifolia L.) is increased in CO2-enriched atmospheres. Ann Allergy Asthma Immunol. 2002; 88:279-282.

4. García-Mozo H, Galán C, Jato V, Belmonte J, Diaz de la Guardia C, Fernandez D, et al. Quercus pollen season dynamics in the Iberian Peninsula: response to meteorological parameters and possible consequences of climate change. Ann Agric Environ Med. 2006;13: 209-224.

5. Beggs PJ, Bambrick HJ. Is the global rise of asthma an early impact of anthropogenic climate change? Environ Health Perspect. 2005; 113:915-919.

6. Williams R. Climate change blamed for rise in hay fever. Nature. 2005:434:105.

7. Galán C, García-Mozo H, Vázquez L, Ruiz L, de la Guardia CD, Trigo MM. Heat requirement for the onset of the Olea europaea L. pollen season in several sites in Andalusia and the effect of the expected future climate change. Int J Biometeorol. 2005;49:184-188.

8. Weryszko-Chmielewska E, Puc M, Piotrowska K. Effect of meteorological factors on Betula, Fraxinus and Quercus pollen concentrations in the atmosphere of Lublin and Szczecin, Poland. Ann Agric Environ Med. 2006;13:243-249.

9. Puc M, Wolski T. Betula and Populus pollen counts and meteorological conditions in Szczecin, Poland. Ann Agric Environ Med. 2002;9:65-69.

10. Laaidi K. Predicting days of high allergenic risk during Betula pollination using weather types. Int J Biometeorol. 2001;45:124-132.

11. Gilmour MI, Jaakkola MS, London SJ, Nel AE, Rogers CA. How exposure to environmental tobacco smoke, outdoor air pollutants, and increased pollen burdens influences the incidence of asthma. Environ Health Perspect. 2006;114:627-633.

12. Moorcroft PR, Pacala SW, Lewis MA. Potential role of natural enemies during tree range expansions following climate change. $J$ Theor Biol. 2006;241:601-616.

13. Ziska LH, Gebhard DE, Frenz DA, Faulkner S, Singer BD, Straka JG. Cities as harbingers of climate change: common ragweed, urbanization, and public health. J Allergy Clin Immunol. 2003;111:290-295.
14. Emberlin J, Detandt M, Gehrig R, Jaeger S, Nolard N, Rantio-Lehtimäki A. Responses in the start of Betula (birch) pollen seasons to recent changes in spring temperatures across Europe. Int J Biometeorol. 2002;46:159-170. Epub 2002 Jul 26 [Published erratum appears in Int J Biometeorol. 2003;47:113-115].

15. Peteet D. Sensitivity and rapidity of vegetational response to abrupt climate change. Proc Natl Acad Sci U S A. 2000;97:1359-1361.

16. Stach A, García-Mozo H, Prieto-Baena JC, Czarnecka-Operacz M, Jenerowicz D, Silny W, et al. Prevalence of Artemisia species pollinosis in western Poland: impact of climate change on aerobiological trends, 1995-2004. J Investig Allergol Clin Immunol. 2007;17:39-47.

17. Breton MC, Garneau M, Fortier I, Guay F, Louis J. Relationship between climate, pollen concentrations of Ambrosia and medical consultations for allergic rhinitis in Montreal 1994-2002. Sci Total Environ. 2006; 370:39-50.

18. Schneiter D, Bernard B, Defila C, Gehrig R. Effect of climatic changes on the phenology of plants and the presence of pollen in the air in Switzerland. Allerg Immunol (Paris). 2002;34:113-116.

19. Steinman H, Donson H, Kawalski M, Toerien A, Potter PC. Bronchial hyper-responsiveness in urban, periurban and rural South African children. Pediatr Allergy Immunol. 2003;14:383-393.

20. World Allergy Organization. GLORIA Food Allergy Module. Available at: http://www.worldallergy.org/educational_programs/gloria/info_form. php?loc $=$ http://www.worldallergy.org/educational_programs/gloria/ modules/gloria_module6_0107.pdf Accessed April 24, 2008.

21. The World Allergy Organization's Online Food Allergy Learning Program and CME. Available at: www.waolearningmodule.org. Accessed April 24, 2008.

22. National Center for Health Statistics. Asthma prevalence, health care use and mortality: United States, 2003-2005. Available at: http:// www.cdc.gov/nchs/products/pubs/pubd/hestats/ashtma03-05/asthma 03-05.htm\#1. Accessed October 2007.

23. Compalati E, Penagos M, Henley K, Canonica GW. Allergy prevalence survey by the World Allergy Organization. Allergy Clin Immunol Int$J$ World Allergy Org. 2007;19:82-90.

24. Warner JO, Kaliner MA, Crisci CD, Del Giacco S, Frew AJ, et al. Allergy practice worldwide: a report by the World Allergy Organization Specialty and Training Council. Allergy Clin Immunol Int-J World Allergy Org. 2006;18:4-10 and Int Arch Allergy Immunol. 2006;139:166-174.

25. Del Giacco S, Rosenwasser LJ, Crisci CD, Frew AJ, Kaliner MA, Lee B-W, et al. What is an allergist? A position statement of the WAO Specialty and Training Council. World Allergy Organization $J$ [serial online] 2008;1:19-20. Available at: http://www.waojournal.org/pt/re/ worldallergy/pdfhandler.01312070-200801000-00006.pdf;jsessionid= LV5h1Sn2h7T91kv3w4M2GYMGpTgMFfLcMbJ59YW4KXmg4w1qV1tq!150813252!181195629!8091!-1.

26. Kaliner MA, Del Giacco S, Crisci CD, Frew AJ, Liu G, Maspero J, et al. for the WAO Specialty and Training Council. Requirements for physician competencies in allergy: key clinical competencies appropriate for the care of patients with allergic or immunologic diseases - a position statement of the World Allergy Organization. World Allergy Organization $J$ [serial online]. 2008;1:42-46. Available at: http://www.waojournal.org/pt/re/worldallergy/abstract.01312070200802000-00005.htm;jsessionid=LV6XK1bLHytqMMyhnv2WwjsJQmn5mGjcrhG5V1Qb1n4pQTLjwkdL!1167962659!181195628!8091!-1.

27. World Health Organization. Asthma: WHO role and activities. Allergic rhinitis and its impact on asthma (ARIA). Available at: http:// www.who.int/respiratory/asthma/activities/en/index.html. Accessed April 24, 2008.

28. World Allergy Organization. GLORIA allergic rhinitis module. Available at: http://www.worldallergy.org/educational_programs/gloria/info_ form.php?loc $=$ http://www.worldallergy.org/educational_programs/ gloria/modules/gloria/module1_0107.pdf. Accessed April 24, 2008.

29. Global Initiative for Asthma. Guidelines and resources. Available at: http://www.ginasthma.com. Accessed April 24, 2008.

30. World Allergy Organization. GLORIA treatment of severe asthma module. Available at: http://www.worldallergy.org/educational_ programs/gloria/modules/gloria_module5_0408.pdf Accessed April 24, 2008.

31. World Allergy Organization. GLORIA rhinosinusitis module. Available at: http://www.worldallergy.org/educational_programs/gloria/info_ 
form.php?loc $=$ http://www.worldallergy.org/educational_programs/ gloria/modules/gloria_module10_0107.pdf Accessed April 24, 2008

32. World Allergy Organization. GLORIA immunotherapy module. Available at: http://www.worldallergy.org/educational_programs/gloria/info_ form.php?loc $=$ http://www.worldallergy.org/educational_programs/ gloria/modules/gloria_module4_0107.pdf. Accessed April 24, 2008.

33. World Allergy Forum: Miami Beach. Sublingual immunotherapy: is there a role? Available at: http://www.worldallergy.org/educational_programs/ world_allergy_forum/miamibeach2006/. Accessed April 24, 2008.

34. World Allergy Organization. The application of monoclonal therapies and therapeutics to asthma and allergy. Available at: http://www. worldallergy.org/educational_programs/world_allergy_forum/ philadelphia2008/welcome.php. Accessed April 24, 2008.

35. Kuhn R. Immunoglobulin E blockade in the treatment of asthma. Pharmacotherapy. 2007;27:1412-1424.
36. Hamelmann E. The rationale for treating allergic asthma with anti-IgE. Eur Respir Rev. 2007;16:61-66.

37. Kemp SF, Lockey RF, Simons FER. For the World Allergy Organization ad hoc Committee on Epinephrine in Anaphylaxis. Epinephrine: the drug of choice for anaphylaxis. Allergy and World Allergy Organization J. In press.

38. World Allergy Organization. GLORIA anaphylaxis module. Available at: http://www.worldallergy.org/educational_programs/gloria/info_form. php?loc $=$ http://www.worldallergy.org/educational_programs/gloria/ modules/gloria_module8_0107.pdf. Accessed April 24, 2008.

39. National Institutes of Health, National Asthma Education and Prevention Program. Expert Panel Report 3: guidelines for the diagnosis and management of asthma. Full report, 2007. Available at: http:// www.nhlbi. nih.gov/guidelines/asthma/asthsumm.htm. Accessed April 24, 2008. 